\title{
New Synthetic Approaches to Biofuels from Lignocellulosic Biomass
}

\author{
Zhu, Ping; Abdelaziz, Omar Y.; Hulteberg, Christian P.; Riisager, Anders
}

Published in:

Current Opinion in Green and Sustainable Chemistry

Link to article, DOI:

10.1016/j.cogsc.2019.08.005

Publication date:

2020

Document Version

Peer reviewed version

Link back to DTU Orbit

\section{Citation (APA):}

Zhu, P., Abdelaziz, O. Y., Hulteberg, C. P., \& Riisager, A. (2020). New Synthetic Approaches to Biofuels from Lignocellulosic Biomass. Current Opinion in Green and Sustainable Chemistry, 21, 16-21.

https://doi.org/10.1016/j.cogsc.2019.08.005

\section{General rights}

Copyright and moral rights for the publications made accessible in the public portal are retained by the authors and/or other copyright owners and it is a condition of accessing publications that users recognise and abide by the legal requirements associated with these rights.

- Users may download and print one copy of any publication from the public portal for the purpose of private study or research.

- You may not further distribute the material or use it for any profit-making activity or commercial gain

- You may freely distribute the URL identifying the publication in the public portal 


\section{Journal Pre-proof}

New Synthetic Approaches to Biofuels from Lignocellulosic Biomass

Ping Zhu, Omar Y. Abdelaziz, Christian P. Hulteberg, Anders Riisager

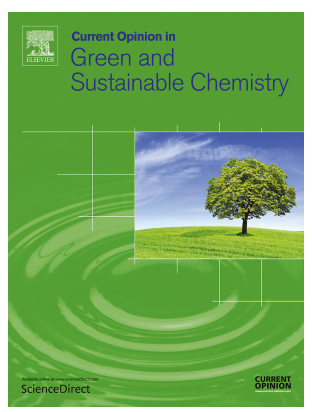

PII:

S2452-2236(19)30039-2

DOI:

https://doi.org/10.1016/j.cogsc.2019.08.005

Reference:

COGSC 291

To appear in: Current Opinion in Green and Sustainable Chemistry

Received Date: 16 August 2019

Accepted Date: 23 August 2019

Please cite this article as: P. Zhu, O.Y. Abdelaziz, C.P. Hulteberg, A. Riisager, New Synthetic Approaches to Biofuels from Lignocellulosic Biomass, Current Opinion in Green and Sustainable Chemistry, https://doi.org/10.1016/j.cogsc.2019.08.005.

This is a PDF file of an article that has undergone enhancements after acceptance, such as the addition of a cover page and metadata, and formatting for readability, but it is not yet the definitive version of record. This version will undergo additional copyediting, typesetting and review before it is published in its final form, but we are providing this version to give early visibility of the article. Please note that, during the production process, errors may be discovered which could affect the content, and all legal disclaimers that apply to the journal pertain.

(C) 2019 Elsevier B.V. All rights reserved. 


\title{
New Synthetic Approaches to Biofuels from Lignocellulosic Biomass
}

Ping Zhu, ${ }^{\mathrm{a} \dagger}$ Omar Y. Abdelaziz, ${ }^{\mathrm{b} \dagger}$ Christian P. Hulteberg, ${ }^{\mathrm{b}}$ and Anders Riisager ${ }^{\mathrm{a} *}$

${ }^{a}$ Centre for Catalysis and Sustainable Chemistry, Department of Chemistry, Technical University of Denmark, Kemitorvet 207, 2800 Kgs. Lyngby, Denmark

${ }^{b}$ Department of Chemical Engineering, Lund University, Naturvetarvägen 14, 22100 Lund, Sweden

${ }^{\dagger}$ These authors contributed equally.

* Corresponding author e-mail: $\underline{\text { ar@ kemi.dtu.dk }}$

\begin{abstract}
Lignocellulose from terrestrial plant biomass is abundant and contains polymeric carbohydrates and lignin; both recognized as attractive renewable feedstock for energy, chemicals and materials as alternatives to fossils to meet the targets for future sustainable development. Liquid biofuels are particularly important renewable commodities because of the vast infrastructure already in place to use them, especially for transportation, and efficient synthetic approaches and viable commercial manufacture processes are under development for both drop-in fuels and new fuel compounds. This work surveys the recent trends in lignocellulosic biomass conversion into fuels, and highlight innovative synthetic approaches based on novel chemo- and bio-catalyst systems and process strategies utilizing both biomass-derived carbohydrates and technical lignin as feedstock.
\end{abstract}

\section{Keywords}


Lignocellulosic biomass; Sustainable resources; Bio-based carbohydrates; Lignin; Biofuels; Green catalysis 


\section{Introduction}

The urge for renewable fuel from biomass-based resources is rapidly increasing and is anticipated to grow further to overcome the shortage of fossil resources and to meet the societal concern for sustainability. Liquid biofuels are of particular importance because of the vast infrastructure already in place to use them, especially for transportation, and synthetic approaches are already accessing commercial operation.

Fossil fuels for transportation consist mainly of liquid hydrocarbons (e.g. alkanes or cycloalkanes) separated into gasoline $\left(\mathrm{C}_{4}-\mathrm{C}_{12}\right)$, diesel $\left(\mathrm{C}_{9}-\mathrm{C}_{25}\right)$ and jet fuel $\left(\mathrm{C}_{8}-\mathrm{C}_{16}\right)$. Biodiesel (bio-esters) and bio-alcohols (especially bioethanol) are attractive substitutes for diesel and gasoline, and are currently mainly produced on large-scale commercially from edible commodities like starch, sugar (e.g. corn or sugarcane) and vegetable oils (i.e. "first generation" biomass) by processes considered established technology. Fatty acids and terpenoid-based biofuels can act as supplements for or replacements of jet fuels, but industrial production technologies are still immature.

The primary resource for the production of biofuels with non-edible feedstock (i.e. "second generation" biomass) is low-value biomass that possesses high cellulose and hemicellulose content, i.e. lignocellulosic biomass including wood chips, crop residues, and municipal waste. Secondary resources include residual oils and fats like, e.g. waste cooking fat from deep-frying and slaughter industry as well as algae ("third-generation" biomass), which also holds promise for biofuel production but so far has it proven difficult to develop economically viable production.

Cellulose is a crystalline polysaccharide comprised of only glucose (hexose) monomer units with resilient $\beta-1,4$ glycoside linkages, while hemicellulose is an amorphous 
polysaccharide comprised of xylose (pentose) and hexoses linked by more weak $\beta$ - and $\alpha$-glycosidic bonds. A general route to synthesize biofuel from such polysaccharides comprise low-temperature deconstruction of the biomass into monomer products, which can be converted into platform compounds, that are either the fuel itself (e.g. ethanol by enzymatic fermentation) or can be further transformed into the biofuel. To improve the energy density of the biofuel, the overall strategies in the synthetic approaches are (1) to reduce the substantial oxygen content of the parent feedstock, and (2) to increase the amount of C-C bonds between biomass-derived intermediates [1].

Lignin, a polyphenolic compound, is also a main component of lignocellulosic and it is, next to cellulose, the most abundant biopolymer in nature. Although different types of lignin and lignin model compounds have been described based on the means of isolation and linkages, the valorization of technical lignin is prioritized from an industrial perspective. Technical lignin is generated as a byproduct from pulp and paper industry or cellulosic ethanol production and presents a sustainable bulk feedstock. In this respect, the synthesis of biofuels from industrial lignin streams holds a great potential to improve the economy of existing pulp mills and debottleneck the recovery boilers onsite. Despite the technical progress reached and the growing importance of environmental sustainability, lignin commercialization is yet to become a success story $[2]$.

This review article concisely summarizes the recent trends in novel synthetic approaches to catalytic conversion of biomass-derived carbohydrates and technical lignin to biofuels.

\section{Biofuels from biomass-derived carbohydrates}


Cellulose, hemicellulose, and their monomers or derivatives are oxygen-containing carbohydrates requiring a series of reaction steps such as, e.g. hydrolysis, dehydration/alkylation, hydrodeoxygenation (HDO) etc. to be converted into liquid biofuels (Figure 1) [3-8]. Cascade or one-pot tandem catalytic reaction processes are preferred operation modes for such processes circumventing cumbersome separation and purification of intermediate chemical compounds, thereby easing processing and enabling efficient utilization of the carbohydrate source.

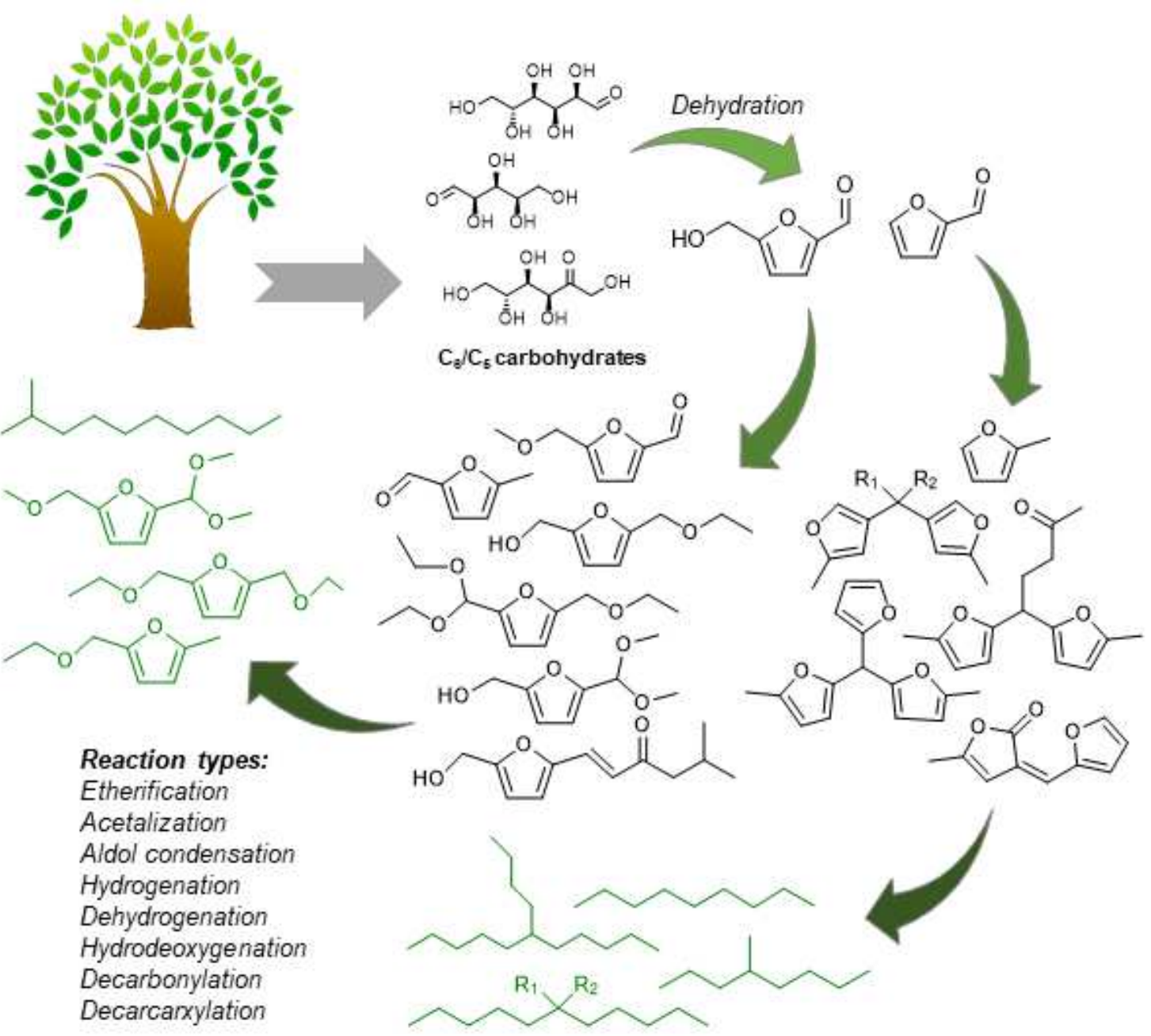

Figure 1. Overview of recent synthetic transformations for production of biofuels and fuel-additives (in green) from biomass-derived carbohydrates via intermediate platform compounds involving cascade and one-pot strategies. 


\subsection{New reaction strategies}

An efficient two-step catalytic cascade process for making jet fuel compatible biofuel includes $\mathrm{NaOH}$-catalyzed aldol condensation of 5-hydroxymethyl furfural (HMF) or furfural with methyl isobutyl ketone (MIBK) to produce branched $\mathrm{C}_{11}$ and $\mathrm{C}_{12}$ furan compounds (yields up to $96 \%$ ) followed by HDO with hydrogen to the branched alkanes 2-methylundecane and 2-methyldecane (yields up to 98\%) using a catalytic system containing $\mathrm{Pd} / \mathrm{C}$ and $\mathrm{Eu}(\mathrm{OTf})_{3}$ [9]. Recently, Li and coworkers have demonstrated an alternative, efficient cascade catalytic process involving alkylation and HDO of 2-methylfuran with solid catalysts and various substrates using pressure tubes for the alkylation followed by HDO of the resulting alkylation solution in a Teflon tube containing another solid catalysts $[10,11]$.

To simplify processing, cascade reactions for the synthesis of biofuels from carbohydrates may also be performed in one-pot as demonstrated for the production of 5-(hydroxymethyl)-2-(dimethoxymethyl)furan from fructose via a two-step dehydration/acetalization process using a facile catalyst $\mathrm{SiO}_{2}-\mathrm{HNO}_{3}$ and $\mathrm{DMSO}-$ methanol biphasic solvent system [12]. However, even more desirable is to operate continuous-flow reactions, which are often preferred for industrial applications. In this respect, Kwon et al. [13] demonstrated selective condensation of 2-methylfuran and

furfural to $\mathrm{C}_{15}$ compounds with supported phosphotungstic acid catalysts in a continuous-flow fixed-bed reactor system, where formation of unwanted viscous tetramers $\left(\mathrm{C}_{20}\right)$ were suppressed. Moreover, Weng et al. [14] applied carbon supported 
phosphated Ru-Mo catalysts in a continuous trickle-bed reactor to convert sorbitol into renewable alkanes and higher alcohols.

\subsection{New catalyst systems}

A variety of other novel homogeneous and heterogeneous catalyst systems offers immense potential in helping to make renewable biofuels into commercial reality [1520]. In this respect, Liu et al. [21] have lately exploited an in-situ generated catalyst system of $\mathrm{HCl}$ and $\mathrm{ZrO}(\mathrm{OH})_{2}$ formed by decomposition of $\mathrm{ZrOCl}_{2} \cdot 8 \mathrm{H}_{2} \mathrm{O}$ in ethanol, which effectively catalyzed the dehydration/etherification of fructose to 5ethoxymethylfurfural (EMF) (gasoline additive) and subsequent reductive etherification of EMF to 2,5-bis(ethoxymethyl)furan (BEMF) using ethanol as H-donor. Furthermore, $\mathrm{Xu}$ et al. [22] found $\mathrm{Mn}_{2} \mathrm{O}_{3}$ be very active and stable for the aldol condensation of furfural and angelica lactone achieving high yield of $96 \%$ of $\mathrm{C}_{10}$ oxygenates under mild reaction conditions. Similar high yield of derived $\mathrm{C}_{9}$ and $\mathrm{C}_{10}$ alkanes (gasoline) were after hydrogenation and HDO obtained of the aldol condensation products over $\mathrm{Pd} / \mathrm{C}$ and $\mathrm{Pd}-\mathrm{FeO}_{\mathrm{x}} / \mathrm{SiO}_{2}$ catalysts, respectively. In an analogous study, Liu et al. [23] reported the aldol condensation of various furfural species with cyclic ketones over a $\mathrm{NaOH}$ catalyst and obtained high yield (>90\%) of the target condensation intermediates under mild conditions $\left(30{ }^{\circ} \mathrm{C} ; 40 \mathrm{~min}\right)$. Afterwards, amorphous zirconium phosphate combined with $\mathrm{Pd} / \mathrm{C}$ catalyzed $\mathrm{HDO}$ of the condensation intermediates to cycloalkanes (gasoline) in good yield $(76 \%)$ at optimized reaction conditions. HDO has also been used to convert sorbitol (sugar alcohol derived from glucose) into high-octane gasoline products with research octane number (RON) higher than 100 in $\sim 70 \%$ yield using zirconium phosphate supported Pd-bimetallic catalysts [24]. In contrast, carbon nanotube supported phosphated Ru-Mo catalysts were found to provide low affinity for 
$\mathrm{C}-\mathrm{C}$ bond cracking of sorbitol resulting instead in high selectivity of $\mathrm{C}_{6}$ products (lower gasoline-range $)$ in gas-phase $\left(\mathrm{C}_{6}\right.$ alkanes, $\left.74.7 \%\right)$ and liquid-phase $\left(\mathrm{C}_{6}\right.$ alkanes and alcohols, 87.8\%) [14].

\subsection{New fuel molecules}

Biomass-derived fuel molecules with high energy density are a new group of materials [25]. Tang et al. [26] demonstrated for the first time the synthesis of 1,1,3-trimethylcyclohexane (jet fuel-range cycloalkane) in good yield (67\%) by coupling the aqueous phase reforming of glycerol and HDO of isophorone, which both are commodities produced industrially in multi-thousand tons per annum scale. Also using readily available feedstock, Liu et al. [27] adopted two steps to convert cellulose into a highdensity mixture of $\mathrm{C}_{12}$ and $\mathrm{C}_{18}$ branched polycycloalkanes with a low freezing point of $48{ }^{\circ} \mathrm{C}$ (winter diesel) in high yield (74.6\%). First, cellulose was selectively converted to 2,5-hexanedione where after it in combination with hydrogen formed branched polycycloalkanes over a dual-bed $\left(25 \% \mathrm{Cu}_{2} \mathrm{Ni} / \mathrm{MgO}-\mathrm{p}\right.$ and $\left.\mathrm{Ni} / \mathrm{H}-\beta\right)$ catalyst system via an aldol condensation-hydrogenation-HDO sequence. Using a similar reaction approach, Wang and co-workers [28] synthesized 1-(3-cyclopentyl)cyclopentyl-2cyclopentylcyclopentane, a new renewable high-density jet or rocket fuel, with a high overall similar yield (70\%) using cyclopenanone as a substrate that can be derived from hemicellulose.

\section{Biofuels from technical lignin}

Lignin-derived fuels can be obtained directly by one-pot depolymerization or through upgrading of bio-oil obtained from biomass degradation by either chemical or biochemical pathways (Figure 2) [29,30]. Under reductive conditions, hydrocarbons can 
be formed in a transparent liquid form, with carbon numbers from $\mathrm{C}_{6}-\mathrm{C}_{9}$ and $\mathrm{C}_{12}-\mathrm{C}_{17}$, covering the gasoline and diesel ranges, respectively [31,32]. Lignin hydrotreatment is normally performed in the presence of a solvent, mainly to suppress condensation and re-polymerization of intermediate radicals. However, solvent recycling can be rather challenging and costly, and solvent-free strategies are thus favored.

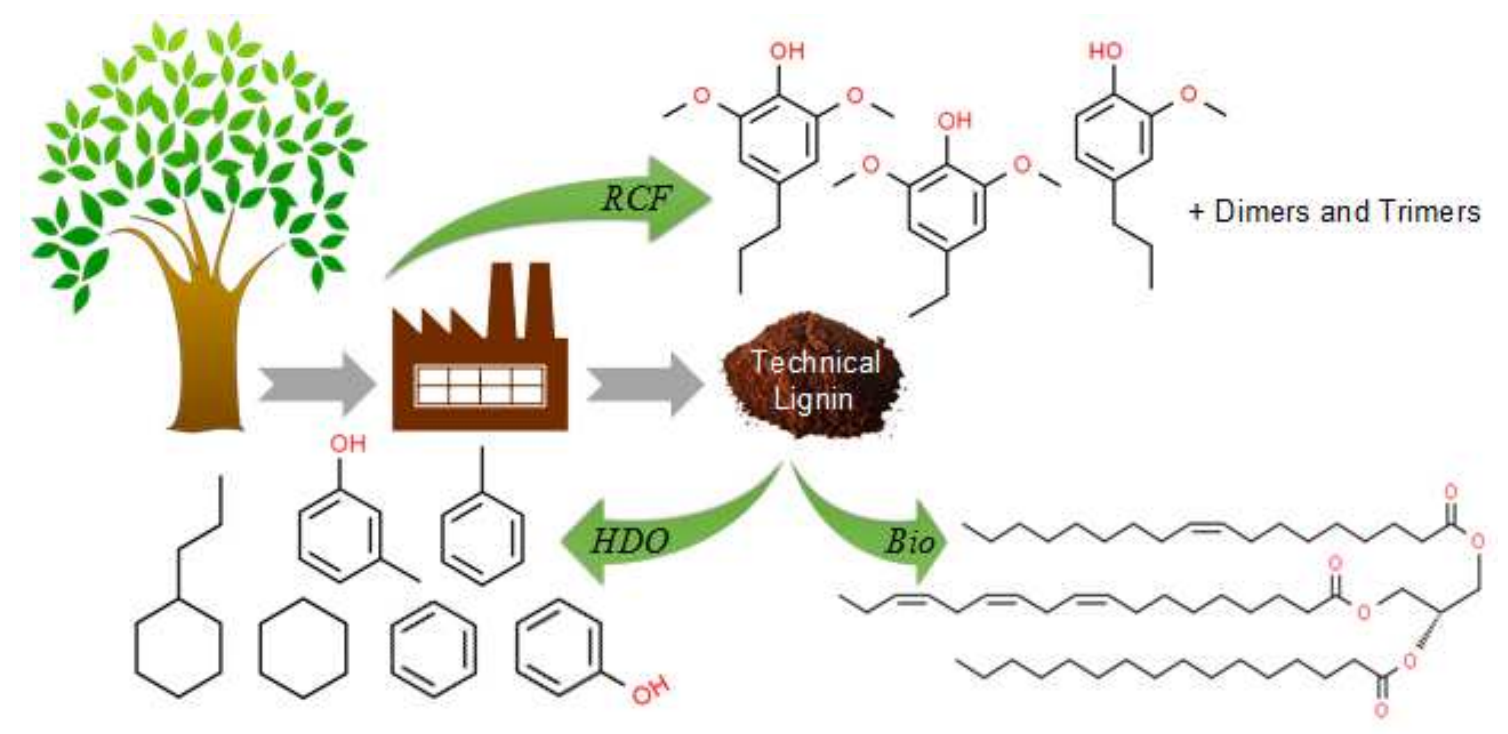

Figure 2. Schematic presentation of recent synthetic approaches to production of biofuel from technical lignin and whole biomass, including reductive catalytic fractionation (RCF), hydrodeoxygenation of technical lignin and lignin-derived oils (HDO), and bioconversion (Bio).

\subsection{New chemical reaction strategies}

Hita et al. [33] demonstrated a process for hydrotreatment of technical lignins using an inexpensive Fe-based limonite catalyst and without using a solvent. Product yields up to $41 \mathrm{wt} \%$ were obtained, containing mostly alkylphenolics and aromatics which can be used for biofuel production. In another example, cyclohexane-derived alkanes in the jetfuel/diesel range were produced via one-pot HDO of softwood lignin using earth- 
abundant metals, including $\mathrm{Fe}, \mathrm{Ni}, \mathrm{Cu}$, and $\mathrm{Zn}$, co-loaded with $\mathrm{Ru}$ on $\mathrm{HY}$ zeolite catalysts [32]. Total yields of hydrocarbon products were in the range $26-32 \mathrm{wt} \%$, and a decrease in the yield of low-molecular-weight gaseous products was observed. The onestep HDO of technical lignin is a promising approach to synthesis of hydrocarbon fuels, but long residence time and high catalyst-to-lignin ratio are often required to overcome low productivity.

Bio-oil, a complex mixture of compounds generated from biomass degradation under relatively harsh conditions, can be upgraded by HDO with hydrogen gas using hydrotreating catalysts. The upgraded products can have comparable quality to traditional fossil fuel pools. Usually, a high hydrogen pressure is required to drive the HDO process when using conventional hydrotreating catalysts. However, recent progress in HDO catalysts for lignin-derived bio-oil upgrading have been introduced, such as molecular sieves supported noble metal and/or transition metal catalysts [34]. Direct upgrading of fast pyrolysis lignin vapors, in situ, was also reported to be successful using conventional hydrotreating catalysts, like HZSM-5 [35]. An organic liquid product was obtained, containing about 70 wt\% oxygen-free aromatics (predominantly benzene and toluene). The intimate contact between lignin and the catalyst during pyrolysis is key to minimize re-polymerization reactions and require further research [35].

A tandem lignin-first biorefinery method has been reported by Román-Leshkov, Beckham and colleagues [36] and further commented and extended by Rinaldi $[37,38]$. This biorefinery paradigm (also termed reductive catalytic fractionation) employs active stabilization [39] and relies on maintaining the carbohydrates intact by selective extraction of lignin as a valuable phenolic resource from whole biomass. Such 
alternative synthetic route may enable the production of hydrocarbons through a sequence of flow reactors, providing improved mass and energy balances all over the process chain. The lignin-derived hydrocarbons generated could serve as replacements for gasoline, diesel, and aviation fuels.

\subsection{New biochemical reaction strategies}

Bioconversion of technical lignin into lipids has emerged recently as a potential route for biofuel synthesis. These lipids can potentially replace fossil-derived chemicals and can contribute, for instance, to a more sustainable route of biodiesel production. Among the different genera of bacterial species, Rhodococcus opacus was reported to produce lipids from technical lignin, e.g. kraft lignin [40,41]. The lipid concentrations were 0.07 and $0.15 \mathrm{~g} / \mathrm{L}$ employing oxygen- [40] and laccase-treatments [41], respectively, however only one oxygen-treatment condition was investigated in the former study. In a very recent study, the parameter space of oxidative depolymerization and the resulting effect on lignin bioconversion has been expanded [42]. The combination of oxygentreatment and subsequent fermentation seems an effective strategy towards improving the bioconversion of lignin into potential drop-in fuel replacements, necessitating further investigation. To date, the highest lipid production utilizing lignin as the carbon source $(1.83 \mathrm{~g} / \mathrm{L})$ was achieved via a combinatorial pretreatment integrated with fedbatch fermentation [42]. However, such high lipid concentration was attained using lignin from corn stover, which quite differs from technical (kraft) lignin in terms of chemical structure and successive breakdown compounds.

\section{Conclusions and future directions}


There are currently many interesting developments in the field of biomass conversion. The identification of new catalyst and reaction systems give promise for improved conversion and utilization of biomass. There are, as described, two radically different approaches to valorization of the biomass, dedicated use or using side-products from existing processing. The first approach is the most promising with respect to production volumes, while the second one is the one with the most near-term promise. The current main chemical processing of biomass is in the context of paper and pulp production and the revenue from the cellulose and hemi-cellulose parts of the wood is the benchmark for producing renewable fuels from the wood. Here, technological questions can be posed, such as if the valorization should line up the existing technical lignin streams readily available from the pulp and paper industry, or should the efforts be directed towards new alternatives, harnessing the lignin-first from biomass components? Finally, it may be speculated if the current pulping mills are willing to change their facilities towards adopting such technologies? Nonetheless, the revenue from the biofuel production, including tax incentives, has to be higher long-term than the alternative revenue from sales of pulp and paper. Another important factor to keep track of is the sustainable silviculture needed for producing sizeable amounts of renewable fuels. Indeed looking at the volumes of transportation fuels needed worldwide and the supply of biomass, it is obvious that the use of biomass in transportation can only be a part of the solution. Along with other approaches such as more efficient vehicles, increasing public transport and electrification of the transport sector.

\section{Conflict of interest statement}

The authors declare no competing financial interests. 


\section{Acknowledgments}

The authors acknowledge funding from the Chinese Scholarship Council (No. 201809505002), the Swedish Foundation for Strategic Research (RBP14-0052), the

Swedish Energy Agency (45241-1), and the Department of Chemistry, Technical University of Denmark.

\section{References}

Papers of particular interest, published within the period of review, have been highlighted as:

* of special interest

** of outstanding interest

*[1] Li H, Riisager A, Saravanamurugan S, Pandey A, Sangwan RS, Yang S, Luque R: Carbon-Increasing Catalytic Strategies for Upgrading Biomass into Energy-Intensive Fuels and Chemicals. ACS Catal. 2018, 8:148-187.

Comprehensive review on selective synthesis of long-chain oxygenates via different CC coupling catalytic processes and other integrated reaction steps to derive corresponding key intermediates or final products.

[2] Wendisch VF, Kim Y, Lee JH: Chemicals from lignin: Recent depolymerization techniques and upgrading extended pathways. Curr. Opin. Green Sustain. Chem. 2018, 14:33-39.

[3] Serrano-Ruiz, JC, Luque R, Sepúlveda-Escribano A: Transformations of biomass-derived platform molecules: from high added-value chemicals to fuels via aqueous-phase processing. Chem. Soc. Rev. 2011, 40:5266-5281. 
[4] Climent, MJ, Corma A, Iborra S: Conversion of biomass platform molecules into fuel additives and liquid hydrocarbon fuels. Green Chem. 2014, 16:516547.

[5] Muraza O: Maximizing diesel production through oligomerization: a landmark opportunity for zeolite research. Ind. Eng. Chem. Res. 2015, 54:781-789.

[6] Addepally U, Thulluri C: Recent progress in production of fuel range liquid hydrocarbons from biomass-derived furanics via strategic catalytic routes. Fuel 2015, 159:935-942.

[7] Moore CM, Jenkins RW, Janicke, MT, Kubic Jr WL, Polikarpov E, Semelsberger TA, Sutton AD: Synthesis of Acetone $\square$ Derived C6, C9, and C12 Carbon Scaffolds for Chemical and Fuel Applications. ChemSusChem 2016, 9:3382-3386.

[8] Maneffa A, Priecel P, Lopez $\square$ Sanchez JA: Biomass $\square$ Derived Renewable Aromatics: Selective Routes and Outlook for $\mathbf{p} \square$ Xylene Commercialisation. ChemSusChem 2016, 9:2736-2748.

[9] Keskivali J, Wrigstedt P, Lagerblom K, Repo T: One-step Pd/C and $\operatorname{Eu}($ OTf $)(3)$ catalyzed hydrodeoxygenation of branched C-11 and C-12 biomass-based furans to the corresponding alkanes. Appl. Catal. A: Gen. 2017, 534:40-45.

**[10] Li H, Gui ZY, Yang S, Qi ZW, Saravanamurugan S, Riisager A: Catalytic Tandem Reaction for the Production of Jet and Diesel Fuel Range Alkanes. Energy Technol. 2018, 6:1060-1066. 
Describes a cascade catalytic process involving alkylation and HDO of 2-methylfuran with different aldehydes to directly produce long-chain alkanes with an exclusive carbon number of $\mathrm{C}_{11}-\mathrm{C}_{17}$.

[11] Wang $\mathrm{Z}$, Li $\mathrm{H}$, Zhao $\mathrm{W}$, Yang $\mathrm{S}$ : Low-temperature and solvent-free production of biomass-derived diesel-range C17 precursor via one-pot cascade acylation-alkylation over $\mathbf{S n}^{4+}$-montmorillonite. J. Ind. Eng. Chem. 2018, 66:325-332.

[12] Qiu G, Wang XC, Huang CP, Li YX, Chen BH: Facile, One-Pot, Two-Step, Strategy for the Production of Potential Bio-Diesel Candidates from Fructose. Catalysts 2017, 7:14.

[13] Kwon JS, Choo H, Choi J-W, Jae J, Jin Suh D, Young Lee K, Ha J-M: Condensation of pentose-derived furan compounds to $\mathrm{C15}$ fuel precursors using supported phosphotungstic acid catalysts: Strategy for designing heterogeneous acid catalysts based on the acid strength and pore structures. Appl. Catal. A: Gen. 2019, 570:238-244.

[14] Weng YJ, Wang TJ, Wang CG, Liu QY, Zhang YL, Duan PG, Wang LL, Yin HX, Liu SJ, Ma LL: Hydrodeoxygenation of Sorbitol into Bio-Alkanes and Alcohols Over Phosphated Ruthenium Molybdenum Catalysts. ChemCatChem 2018, 10:5032-5038.

[15] Trombettoni V, Lanari D, Prinsen P, Luque R, Marrocchi A, Vaccaro L: Recent advances in sulfonated resin catalysts for efficient biodiesel and bio-derived additives production. Prog. Energy Combust. Sci. 2018, 65:136-162. 
[16] Sudarsanam P, Zhong RY, Van den Bosch S, Coman SM, Parvulescu VI, Sels BF: Functionalised heterogeneous catalysts for sustainable biomass valorisation. Chem. Soc. Rev. 2018, 47:8349-8402.

[17] Singh SK: Heterogeneous Bimetallic Catalysts for Upgrading BiomassDerived Furans. Asian J. Org. Chem. 2018, 7:1901-1923.

[18] Murphy BM, Xu BJ: Foundational techniques for catalyst design in the upgrading of biomass-derived multifunctional molecules. Prog. Energy Combust. Sci. 2018, 67:1-30.

[19] Bender TA, Dabrowski JA, Gagne MR: Homogeneous catalysis for the production of low-volume, high-value chemicals from biomass. Nature Rev. Chem. 2018, 2:35-46.

[20] Zhang ZR, Song JL, Han BX: Catalytic Transformation of Lignocellulose into Chemicals and Fuel Products in Ionic Liquids. Chem. Rev. 2017, 117:6834-6880.

**[21] Liu H, Tang X, Hao WW, Zeng XH, Sun Y, Lei TZ, Lin L: One-pot tandem conversion of fructose into biofuel components with in-situ generated catalyst system. J. Energy Chem. 2018, 27:375-380.

Describes one-pot tandem conversion of fructose into biofuel components by dehydration/etherification and subsequent reductive etherification using ethanol as $\mathrm{H}$ donor with an in-situ generated zirconium catalyst.

[22] Xu JL, Li N, Yang XF, Li GY, Wang AQ, Cong Y, Wang XD, Zhang T: Synthesis of Diesel and Jet Fuel Range Alkanes with Furfural and Angelica Lactone. ACS Catal. 2017, 7:5880-5886. 
[23] Liu QY, Zhang CH, Shi N, Zhang XH, Wang CG, Ma LL: Production of renewable long-chained cycloalkanes from biomass-derived furfurals and cyclic ketones. $R S C A d v .2018, \mathbf{8}: 13686-13696$.

[24] Kwon EE, Kim YT, Kim HJ, Lin KYA, Kim KH, Lee J, Huber GW: Production of high-octane gasoline via hydrodeoxygenation of sorbitol over palladium-based bimetallic catalysts. J. Environ. Manage. 2018, 227:329-334.

[25] Zhang X, Pan L, Wang L, Zou J-J: Review on synthesis and properties of high-energy-density liquid fuels: Hydrocarbons, nanofluids and energetic ionic liquids. Chem. Eng. Sci. 2018, 180:95-125.

[26] Tang H, Li N, Li SS, Chen F, Li GY, Wang AQ, Cong Y, Wang XD, Zhang T: Synthesis of jet fuel rang cycloalkane from isophorone with glycerol as a renewable hydrogen source. Catal. Today 2017, 298:16-20.

*[27] Liu YT, Li GY, Hu YC, Wang AQ, Lu F, Zou JJ, Cong Y, Li N, Zhang T: Integrated Conversion of Cellulose to High-Density Aviation Fuel. Joule 2019, 3:1028-1036.

Describes an effective and integrated strategy for the catalytic production of highdensity aviation fuels containing a mixture of $\mathrm{C}_{12}$ and $\mathrm{C}_{18}$ branched polycycloalkanes from cellulose via an aldol condensation-hydrogenation-HDO sequence.

[28] Wang W, Li N, Li GY, Li SS, Wang WT, Wang AQ, Cong Y, Wang XD, Zhang T: Synthesis of Renewable High-Density Fuel with Cyclopentanone Derived from Hemicellulose. ACS Sustainable Chem. Eng. 2017, 5:1812-1817.

[29] Ren T, Qi W, Su R, He Z: Promising Techniques for Depolymerization of Lignin into Value-added Chemicals. ChemCatChem 2019, 11:639-654.

[30] Becker J, Wittmann C: A field of dreams: Lignin valorization into chemicals, 
materials, fuels, and health-care products. Biotechnol. Adv. 2019, doi:10.1016/j.biotechadv.2019.02.016.

[31] Shao Y, Xia Q, Dong L, Liu X, Han X, Parker SF, Cheng Y, Daemen LL, Ramirez-Cuesta AJ, Yang S, et al.: Selective production of arenes via direct lignin upgrading over a niobium-based catalyst. Nat. Commun. 2017, 8:16104.

[32] Wang H, Ruan H, Feng M, Qin Y, Job H, Luo L, Wang C, Engelhard MH, Kuhn E, Chen X, et al.: One-Pot Process for Hydrodeoxygenation of Lignin to Alkanes Using Ru-Based Bimetallic and Bifunctional Catalysts Supported on Zeolite Y. ChemSusChem 2017, 10:1846-1856.

*[33] Hita I, Heeres HJ, Deuss PJ: Insight into structure-reactivity relationships for the iron-catalyzed hydrotreatment of technical lignins. Bioresour. Technol. 2018, 267:93-101.

Describes an effective route suitable for processing technical lignin via hydrotreatment using an inexpensive Fe-based limonite catalyst under solvent-free conditions, obtaining lignin-oils composed mainly of alkylphenolics and aromatics.

[34] Li X, Chen G, Liu C, Ma W, Yan B, Zhang J: Hydrodeoxygenation of ligninderived bio-oil using molecular sieves supported metal catalysts: A critical review. Renew. Sustain. Energy Rev. 2017, 71:296-308.

[35] Zhou G, Jensen PA, Le DM, Knudsen NO, Jensen AD: Direct upgrading of fast pyrolysis lignin vapor over the HZSM-5 catalyst. Green Chem. 2016, 18:1965-1975.

**[36] Anderson EM, Stone ML, Katahira R, Reed M, Beckham GT, Román-Leshkov Y: Flowthrough Reductive Catalytic Fractionation of Biomass. Joule 2017, 1:613-622. 
Demonstrates the first RCF attempt in a flowthrough mode to semicontinuously extract and depolymerize lignin into monomers, enabling better understanding of mechnistic steps of lignin fractionation compared to traditional batch mode processing.

[37] Rinaldi R: A Tandem for Lignin-First Biorefinery. Joule 2017, 1:427-428.

[38] Cao Z, Dierks M, Clough MT, de Castro IBD, Rinaldi R: A Convergent Approach for a Deep Converting Lignin-First Biorefinery Rendering HighEnergy-Density Drop-in Fuels. Joule 2018, 2:1118-1133.

[39] Renders, T, Van den Bosch, S, Koelewijn, SF, Schutyser, W, Bels, BF: Ligninfirst biomass fractionation: the advent of active stabilisation strategies. Energy Environ. Sci. 2017, 10:1551-1557.

[40] Zhao C, Xie S, Pu Y, Zhang R, Huang F, Ragauskas AJ, Yuan JS: Synergistic enzymatic and microbial lignin conversion. Green Chem. 2016, 18:1306-1312.

*[41] Abdelaziz OY, Ravi K, Mittermeier F, Meier S, Riisager A, Lidén G, Hulteberg CP: Oxidative Depolymerization of Kraft Lignin for Microbial Conversion. ACS Sustainable Chem. Eng. 2019, 7:11640-11652.

Demonstrates the potential of oxidative depolymerization as a means of pretreatment for bioconversion of technical lignin, exploring the parameter space of oxidative treatment and the resulting effect on lignin conversion by various bacterial species.

[42] Liu Z-H, Xie S, Lin F, Jin M, Yuan JS: Combinatorial pretreatment and fermentation optimization enabled a record yield on lignin bioconversion. Biotechnol. Biofuels 2018, 11:21. 
Declarations of interest: none 